\title{
Crop protection: new strategies for sustainable development
}

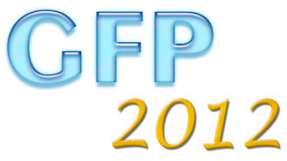

\author{
Jean-François Chollet • Michel Couderchet • Jean-Louis Bonnemain
}

Received: 25 November 2013 / Accepted: 16 January 2014 / Published online: 4 February 2014

(C) Springer-Verlag Berlin Heidelberg 2014

GFP 2012 was the 42nd congress organized by the French Group of Pesticide research ("Groupe Français des Pesticides", GFP), an association created in 1977 by a group of scientists from several French universities and research institutes. Initially, this conference was held twice a year, but nowadays, the adopted rhythm is once a year over a period of 3 days, usually in May. All scientific and technical aspects of the synthesis, reactivity, mode of action, toxicology, ecotoxicology, and environmental fate of pesticides are discussed.

In this special issue, ESPR publishes 17 articles that are based on oral presentations at GFP 2012 in Poitiers. It covers the latest advances in the field of pesticide research with a special focus on innovative strategies for plant protection. This key theme was chosen by the organizing team according to the main research conducted in the location hosting the conference, namely, original strategies to confer systemicity to nonmobile compounds. The purpose of this research is to improve the bioavailability of active compounds, thereby reducing the quantity of pesticides used and pollution. It also

Responsible editor: Philippe Garrigues

J.-F. Chollet $(\bowtie)$

Institut de Chimie des Milieux et Matériaux de Poitiers, Unité Mixte de Recherche CNRS 7285, Université de Poitiers, TSA 51106, 4 rue Michel Brunet, 86073 Poitiers Cedex 9, France

e-mail: jfcholle@univ-poitiers.fr

\section{Couderchet}

Unité de Recherche Vignes et Vin de Champagne, EA 4707, Université de Reims Champagne-Ardenne, BP 1039, 51687 Reims Cedex 2, France

e-mail: michel.couderchet@univ-reims.fr

\section{J.-L. Bonnemain}

Laboratoire Écologie et Biologie des Interactions, Unité Mixte de Recherche CNRS 7267, Université de Poitiers, TSA 51106, 3 rue Jacques Fort, 86073 Poitiers Cedex 9, France

e-mail: jl.bonnemain@voila.fr aims at managing parasites that remain uncontrolled because of their location, e.g., fungi responsible for grapevine trunk diseases.

In 2008, France, which is the fourth largest market, behind the USA, Brazil, and Japan, has implemented an action plan called "Écophyto". The Écophyto plan embodies the commitment given by the authorities, industry professionals, and representatives of civil society to cut the nationwide use of pesticides by $50 \%$ within 10 years, if possible (Ministère de l'Agriculture et de la Pêche 2008). The most notable goal of Écophyto is to reduce the dependency of farms on plant protection products, without affecting agricultural yields and maintaining high levels both in terms of quality and quantity. In this context, the aim of the conference was to provide some answers to current societal challenges, i.e., producing larger amounts of food for an exponentially growing population while reducing agronomic inputs for pest and weed control, thereby reducing pollution as well as potential toxicity to the environment or human health.

In order to achieve these various objectives, GFP 2012 was organized in four sessions as follows:

- Innovative approaches to reduce applied doses of active ingredients: new formulations of existing molecules, development of predictive models of pest attacks, optimizing the bioavailability of active compounds...

- Alternative pest control methods: allelopathy, stimulation of plant defenses, new families of plant protection products derived from natural molecules, new modes of action and biochemical targets...

- Quality of air, water, soil, food, and ecotoxicology: monitoring of transfers and transformations of pesticides in the environment, environmental contamination, innovative remediation processes, analytical methods...

- Risks associated with the use of pesticides: impacts on human and animal health, epidemiology, prevention.... 
A quite elegant approach to reduce quantities of pesticides used is to model the parasitic pressure in order to apply treatments only as necessary and not preventively as it is commonly done. El Jarroudi et al. (2013) from the University of Liège in Belgium presented an empirical approach for monitoring the infection and progress of leaf rust (caused by Puccinia triticina) during stem elongation on winter wheat. Coupling this empirical approach to a mechanistic model simulating leaf emergence and development has led to a decision support system (DSS) that allowed to reduce the numbers of fungicide applications while maintaining good control of brown rust disease in winter wheat (El Jarroudi et al. 2014). This strategy can also be applied to invertebrate pests. Ciss et al. (2013) from the Institut National de la Recherche Agronomique (INRA) of Rennes developed a spatiotemporal model for predicting grain aphid population dynamics and optimizing insecticide sprays at the scale of continental France. The model intends to complete the punctual forecasting provided by older models by a comprehensive spatial view on a larger area and leads to the diminution of insecticide sprayings in wheat crops. Another strategy to reduce the amount of agrochemical inputs is to limit unwanted degradation of the active ingredient that could affect biological efficiency. Particularly, photolysis may be a significant route of pesticide dissipation on crops. Spraying strong absorbing compounds (photoprotector) along with pesticide is an attractive strategy to prevent the photodegradation phenomenon. Trivella and Richard (2013) from the University of ClermontFerrand studied photoprotection of sulcotrione by a grape wine extract. The resulting decrease of degradation is a complex interaction of UV screening and antioxidant effects.

Among alternative pest control methods, biological control must be considered. Delaunois et al. (2013) from the University of Reims have examined elicitors as an alternative strategy to pesticides in grape wine. This review aims at providing an overview of the current knowledge on these molecules and highlights their potential efficacy in laboratory experiments in controlled conditions and also in vineyards. The authors also point out the difficulty of transferring results obtained with elicitor in the laboratory or greenhouse to the vineyard, and thus, they propose some ideas for improving their efficacy in noncontrolled conditions. Gerbore et al. (2013) from the University and INRA of Bordeaux discuss the advantages and limitations of biological control of plant pathogens through the case study of the oomycete Pythium oligandrum, with regard to its interactions with the incredibly complex agrosystems. They conclude that a major challenge for the scientific community in the coming years will be to (1) focus on field experiments, which, although they are time consuming, are of the utmost importance, and (2) make growers sensitive to these new kinds of biological control methods. To identify new environment-friendly plant protection compounds, allelopathy may be a promising way and, in particular, to develop new synthetic herbicide families. Some years ago, L-meta-tyrosine, a herbicidal nonprotein amino acid, was isolated from fine fescue grasses. This compound is characterized by its almost immediate microbial degradation in soil. Movellan et al. (2013) from the University of Poitiers describe the synthesis of nine analogs of L-metatyrosine whose degradation is slower. In bioassays, these compounds induced a large range of biological responses, such as root growth inhibition of lettuce seedling equivalent to that obtained with $m$-tyrosine or an increase of primary root growth concomitant with a delay of secondary root initiation.

Besides these original approaches to reduce the environmental impact of plant protection compounds, the other topics that were discussed were those that are the most commonly discussed in the various congresses of GFP and, particularly, the fate and transfer of pesticides in the environment. Lefrancq et al. (2013) from the University of Strasbourg have studied the contribution of nontarget areas (such as forests or road networks) to fungicides transport in runoff, both at the plot and catchment scales. Their work underlines that nontarget areas within the catchment largely contribute to the overall load of runoff-associated fungicides (kresoxim-methyl and cyazofamid in this case). Passeport et al. (2013) from Irstea (Institut National de Recherche en Sciences et Technologies pour l'Environnement et l'Agriculture) of Antony and Villeurbanne present the potential and the functioning principles of a "wet" forest buffer zone for reducing concentrations and loads of several pesticides in a stream (glyphosate, isoproturon, metazachlor, azoxystrobin, epoxiconazole, and cyproconazole). Low concentrations were observed for all pesticides at the forest buffer outlet thus demonstrating the efficiency of wet forest buffer zone for pesticide dissipation. With this work, Elodie Passeport received the Phytopharma Award granted to the best French doctoral thesis of the year on a theme related to plant protection products (Chollet et al. 2013).

In the same spirit, Vallee et al. (2013) from the University of Nancy looked into the sorption of six pesticides on four substrates (two soils, sediment, and straw) commonly found in a pond and ditch in Lorraine (France). Their objective was to assess the efficiency of these buffer zones, in particular constructed wetlands. This study leads to the conclusion that establishment and maintenance of plants and straw filters should be promoted to optimize sorption processes and the efficiency of ponds and ditches in reducing surface water pollution. Evaluating leaching potential of pesticides is important to prevent groundwater contamination. Langeron et al. (2012) from the University of Reims have compared leaching potential of phenylurea herbicides in a calcareous soil using column elution and batch studies. They conclude that within phenylurea family, it was possible to link batch experiments with column experiments, which are more realistic than batch. Moreover, they also demonstrated that the number and nature 
of halogen atoms on the phenyl ring had an important influence on leaching. When old designed molecules were used on a large scale, this sometimes led to pollutions of soil or groundwater that must be addressed. This was the case with chlordecone, an organochlorine insecticide widely used in a recent past in the banana plantations in the French West Indies. In this regard, Merlin et al. (2013) from the University of Dijon and the INRA of Dijon and Versailles present a novel approach that could lead to a remediation process. They characterize chlordecone-tolerant fungal populations isolated from long-term polluted tropical volcanic soil in the French West Indies. Among major species, Fusarium oxysporum MIAE01197 was shown to not only tolerate high concentration of chlordecone, but also, its growth was stimulated by chlordecone. This suggests that in response to longterm exposure to chlordecone in contaminated soils, fungal species adapted to the pesticide. Among possible processes, biosorption and degradation abilities of $F$. oxysporum MIAE01197 were shown to be involved in the dissipation of chlordecone. Within the same research program, MartinLaurent et al. (2013) developed a method for detection and quantification of chlordecone in contaminated soils by gas chromatography-mass spectrometry using the ${ }^{13} \mathrm{C}_{10^{-}}$ chlordecone stable isotope as a tracer. It should be useful for monitoring the fate of chlordecone in soils of the French West Indies in the framework of the national plan for chlordecone.

The risk associated with pesticide use is also an important factor to understand. Sometimes, substitutes of pesticides can also have unpredictable adverse effects. Carayon et al. (2013) from the University of Albi studied the persistence of thymol, a natural substance increasingly used as an alternative to pesticides in the control of Varroa destructor mite, and its effects on the phototactic behavior of the honeybee, Apis mellifera. In the light of their results related to behavioral data, the persistence of thymol in waxes, and the high load on bees, it appears to be important to investigate the long-term effects of thymol in beehives. Aquatic organisms are generally very sensitive to pesticides, and it is therefore important to study the impact of molecule alone or in combination to detect possible synergistic action. Moreau et al. (2013) from the Institut Français pour la Recherche et l'Exploitation de la Mer (Ifremer) of La Tremblade and Nantes showed that Pacific oyster (Crassostrea gigas) hemocytes are not affected by a mixture of 14 pesticides or metaldehyde alone in shortterm in vitro assays. They conclude that it could be assumed that these oyster cells were resistant to pesticide exposure in tested conditions, and developing in vivo assays appears necessary to better understand the effects of pollutants on immune system in mollusks. Ayadi et al. (2013) from the Mediterranean Agronomic Institute of Montpellier focused on the consequences of intensive agriculture and, in particular, how to evaluate the impact of phytosanitary products on human health and the environment. They present the
SimPhy simulation game which places the actors from a given region directly into a situation in which they manage farms while under pressure to reduce phytosanitaries (quantity and toxicity). The application focused on the Merja Zerga catchment area in Morocco. Finally, through a historic cohort study, Limousi et al. (2013) from the University of Poitiers showed that area deprivation can modify the association between exposure to a nitrate and low-dose atrazine metabolite mixture in drinking water and small for gestational age (SGA). According to the authors, the results demonstrate an effect of socioeconomic context on the relationship between SGA risk and exposure to a mixture of atrazine metabolites and nitrates in drinking water during the second trimester of pregnancy.

The topics covered in this special issue are diverse, and they reflect the quality of the research presented in the GFP congresses in the sensitive field of pesticides. The guest editors hope that this issue will stimulate constructive discussions and interdisciplinary research to open up new perspectives in this exciting field linking crop protection and pollution.

\section{References}

Ayadi H, Le Bars M, Le Grusse P, Mandart E, Fabre J, Bouaziz A, Bord J (2013) SimPhy: a simulation game to lessen the impact of phytosanitaries on health and the environment - the case of Merja Zerga in Morocco. Environ Sci Pollut Res. doi:10.1007/s11356-013-2244-2

Carayon JL, Tene N, Bonnafe E, Alayrangues J, Hotier L, Armengaud C, Treilhou M (2013) Thymol as an alternative to pesticides: persistence and effects of Apilife Var on the phototactic behavior of the honeybee Apis mellifera. Environ Sci Pollut Res. doi:10.1007/s11356-013-2143-6

Chollet J-F, Couderchet M, Bonnemain J-L (2013) 42nd congress of the "Groupe Français des Pesticides" (French Group of Pesticide research - GFP 2012); ENSIP, Poitiers, France, May 30-June 1, 2012. Environ Sci Pollut Res. doi:10.1007/s11356-013-2179-7

Ciss M, Parisey N, Moreau F, Dedryver C-A, Pierre J-S (2013) A spatiotemporal model for predicting grain aphid population dynamics and optimizing insecticide sprays at the scale of continental France. Environ Sci Pollut Res. doi:10.1007/s11356-013-2245-1

Delaunois B, Farace G, Jeandet P, Clement C, Baillieul F, Dorey S, Cordelier S (2013) Elicitors as alternative strategy to pesticides in grapevine? Current knowledge on their mode of action from controlled conditions to vineyard. Environ Sci Pollut Res. doi:10.1007/s11356-013-1841-4

El Jarroudi M, Kouadio L, Delfosse P, Tychon B (2013) Brown rust disease control in winter wheat: I. Exploring an approach for disease progression based on night weather conditions. Environ Sci Pollut Res. doi:10.1007/s11356-013-2463-6

El Jarroudi M, Kouadio L, Giraud F, Delfosse P, Tychon B (2014) Brown rust disease control in winter wheat: II. Exploring the optimization of fungicide sprays through a decision support. Environ Sci Pollut Res. doi:10.1007/s11356-014-2557-9

Gerbore J, Benhamou N, Vallance J, Le Floch G, Grizard D, RegnaultRoger C, Rey P (2013) Biological control of plant pathogens: advantages and limitations seen through the case study of Pythium oligandrum. Environ Sci Pollut Res. doi:10.1007/s11356-013-1807-6

Langeron J, Sayen S, Couderchet M, Guillon E (2012) Leaching potential of phenylurea herbicides in a calcareous soil: comparison of column elution and batch studies. Environ Sci Pollut Res. doi:10.1007/ s11356-012-1244-y 
Lefrancq M, Payraudeau S, Garcia Verdu AJ, Maillard E, Millet M, Imfeld G (2013) Fungicides transport in runoff from vineyard plot and catchment: contribution of non-target areas. Environ Sci Pollut Res. doi:10.1007/s11356-013-1866-8

Limousi F, Albouy-Llaty M, Carles C, Dupuis A, Rabouan S, Migeot V (2013) Does area deprivation modify the association between exposure to a nitrate and low-dose atrazine metabolite mixture in drinking water and small for gestational age? A historic cohort study. Environ Sci Pollut Res. doi:10.1007/s11356-013-1893-5

Martin-Laurent F, Sahnoun MM, Merlin C, Vollmer G, Lubke M (2013) Detection and quantification of chlordecone in contaminated soils from the French West Indies by GC-MS using the 13C10chlordecone stable isotope as a tracer. Environ Sci Pollut Res. doi: 10.1007/s11356-013-1839-y

Merlin C, Devers M, Crouzet O, Heraud C, Steinberg C, Mougin C, Martin-Laurent F (2013) Characterization of chlordecone-tolerant fungal populations isolated from long-term polluted tropical volcanic soil in the French West Indies. Environ Sci Pollut Res. doi:10. 1007/s11356-013-1971-8

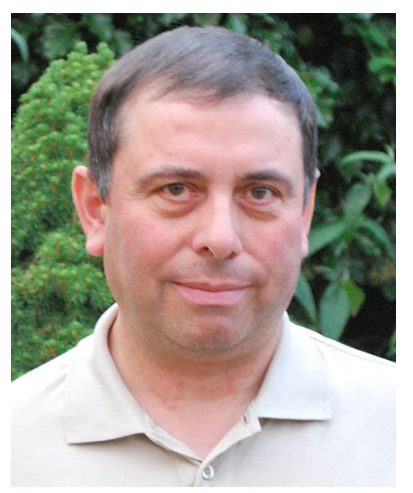

Jean-François Chollet is Chargé de Recherches at the IC2MP (Institute of Chemistry of Poitiers: Materials and Natural Resources), a CNRS-Poitiers University joined unit. He works at organic chemistry/plant biology interface, with a special focus on the mobility of xenobiotics and natural products in plants. In particular, he developed original strategies to confer systemicity to non-mobile compounds. He is also interested in the mode of transport of salicylic acid - a stress hormone in plants - by highlighting the intervention of a carrier with an unconventional method. He also imagined a novel use for zeolites, using them to create controlled release environmental friendly formulations of plant protection products or nutrients. Current research topics are devoted to the development of systemic profungicides, which can then release by enzymatic cleavage the active ingredient in the plant tissues.

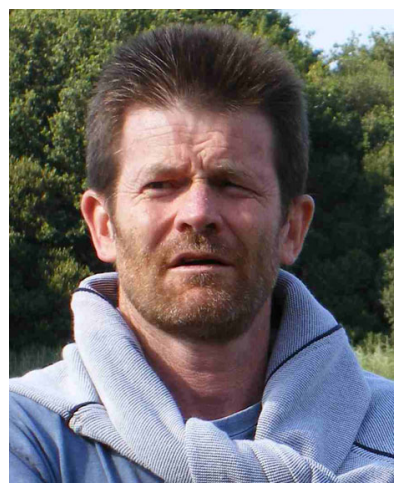

Michel Couderchet is Professor in the Unité de Recherche Vigne et Vin de Champagne at the University of Reims. His work has been devoted to pesticides since the late 1980's in laboratories in the USA, Germany, and France. His main interests include the effects of pesticides on the physiology of target and non-target plants, the behavior, fate, and bioavailability of pesticide in the environment, ecotoxicology of pesticides and soil and water pollution by these compounds. He has coauthored 50 peer-reviewed papers in these domains and participated in over 100 poster or oral presentations in conferences around the world. He has been elected president of the GFP in 2005 and reelected ever since.
Ministère de l'Agriculture et de la Pêche (2008) Écophyto 2018. <http:// agriculture.gouv.fr/IMG/pdf/PLAN_ECOPHYTO_2018 eng.pdf>

Moreau P, Burgeot T, Renault T (2013) Pacific oyster (Črassostrea gigas) hemocyte are not affected by a mixture of pesticides in short-term in vitro assays. Environ Sci Pollut Res. doi:10.1007/s11356-013-1931-3

Movellan J, Rocher F, Chikh Z, Marivingt-Mounir C, Bonnemain J-L, Chollet J-F (2013) Synthesis and evaluation as biodegradable herbicides of halogenated analogs of L-meta-tyrosine. Environ Sci Pollut Res. doi:10.1007/s11356-012-1302-5

Passeport E, Richard B, Chaumont C, Margoum C, Liger L, Gril JJ, Tournebize J (2013) Dynamics and mitigation of six pesticides in a "wet" forest buffer zone. Environ Sci Pollut Res. doi:10.1007/ s11356-013-1724-8

Trivella A, Richard C (2013) New insights into pesticide photoprotection. Environ Sci Pollut Res. doi:10.1007/s11356-013-1490-7

Vallee R, Dousset S, Billet D, Benoit M (2013) Sorption of selected pesticides on soils, sediment and straw from a constructed agricultural drainage ditch or pond. Environ Sci Pollut Res. doi:10.1007/ s11356-013-

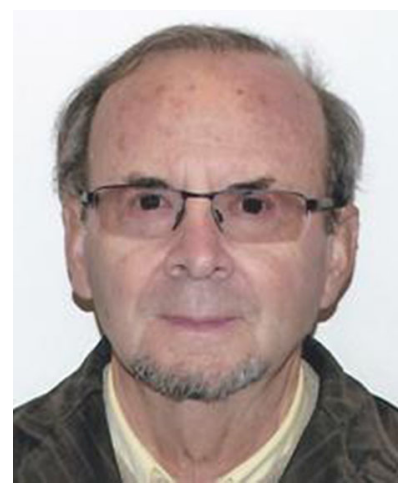

Jean-Louis Bonnemain is Professor Emeritus at Poitiers University. His works have been devoted to 1 - The membrane and long distance transports of nutrients (sugars, aminoacids) and hormones (auxin, gibberellins, abscisic acid) in relation with plant growth, development and productivity, 2- The membrane properties of highly specialized cells such as companion cells, transfer cells and motor cells, 3The membrane and long distance transport of stress signals, 4- The effects of biotic and abiotic stresses on metabolism and compartmentation of nutrients and 5- The systemicity of pesticides and propesticide strategies. From 1977 to 1992, he was the Director of the Laboratory of Plant Physiology and Biochemistry (ERA CNRS 701 then URA CNRS 574) at Poitiers University. Between 1973 and 1999, he was expert in various research organisms, mainly at the French Ministry of Research and Technology and Ministry of Universities. He was elected Correspondent (1978) and then Member (1992) of the French Academy of Sciences (section of Integrative Biology). 